\title{
Comparative Pharmacokinetics of Puerarin Alone and in Pueraria mirifica Extract in Female Cynomolgus Monkeys
}

Authors

Sureerat Namken ${ }^{1}$, Phanit Songvut ${ }^{2,3}$, Nitra Nuengchamnong ${ }^{4}$, Taratorn Kemthong ${ }^{5}$, Phisit Khemawoot ${ }^{6,7}$, Suchinda Malaivijitnond 1,5,6

\section{Affiliations}

1 Department of Biology, Faculty of Science, Chulalongkorn University, Bangkok, Thailand

2 Department of Pharmacology and Physiology, Faculty of Pharmaceutical Sciences, Chulalongkorn University, Bangkok, Thailand

3 Translational Research Unit, Chulabhorn Research Institute, Bangkok, Thailand

4 Science Laboratory Centre, Faculty of Science, Naresuan University, Phitsanulok, Thailand

5 National Primate Research Center of ThailandChulalongkorn University, Saraburi, Thailand

6 Preclinical Pharmacokinetics and Interspecies Scaling for Drug Development Research Unit, Chulalongkorn University, Bangkok, Thailand

7 Chakri Naruebodindra Medical Institute, Faculty of Medicine Ramathibodi Hospital, Mahidol University, Samutprakarn, Thailand

Key words

bioavailability, Fabaceae, Macaca fascicularis, pharmacokinetics, Pueraria mirifica, puerarin

received

accepted after revision

published online

May 5, 2020

September 21, 2020

October 15, 2020

Bibliography

Planta Med 2021; 87: 395-403

DOI 10.1055/a-1271-7092

ISSN 0032-0943

C 2020. Thieme. All rights reserved.

Georg Thieme Verlag KG, Rüdigerstraße 14,

70469 Stuttgart, Germany

\section{Correspondence}

Suchinda Malaivijitnond, Ph.D.

National Primate Research Center of Thailand-Chulalongkorn University

18110 Saraburi, Thailand

Phone: + 6622185275, Fax: + 6622185275

Suchinda.m@chula.ac.th
Correspondence

Phisit Khemawoot, Ph.D.

Chakri Naruebodindra Medical Institute, Faculty of Medicine

Ramathibodi Hospital, Mahidol University

Samut Prakarn 10540, Thailand

Phone: + 6628395161, Fax: + 6628395161

phisit.khe@mahidol.ac.th

\section{ABSTRACT}

Pueraria mirifica is an endemic Thai plant that has been used for rejuvenation and in the relief of various aging diseases. Puerarin is one of the major isoflavones found in this plant and shows several pharmacological activities in relation to the Thai traditional use of $P$. mirifica. Therefore, comparative pharmacokinetics of pure puerarin alone and that in a P. mirifica extract in cynomolgus monkeys were conducted in order to investigate the pharmacokinetic profiles of the 2 preparations. To this end, puerarin and $P$. mirifica extract, at an equivalent dose of $10 \mathrm{mg} / \mathrm{kg}$ of puerarin, were orally dosed to adult female monkeys for 7 consecutive days. A single intravenous injection of puerarin at a dose of $1 \mathrm{mg} / \mathrm{kg}$ was also peformed. Serial blood samples and excreta were collected from $0-24 \mathrm{~h}$ and $0-48 \mathrm{~h}$ after dosing. Determination of the puerarin levels and its metabolites in biological samples was conducted by liquid chromatography tandem mass spectrometry. Plasma levels of aspartate aminotransferase, alanine aminotransferase, and creatinine fluctuated in the normal range, with no abnormal physical signs in the animal. The absolute oral bioavailability of puerarin was approximately $1 \%$ in both preparations. Accumulation of puerarin was found after oral dosing for 7 consecutive days in both groups. Major metabolites of puerarin found in monkeys were hydroxylation and deglycosylation products. A negligible amount of unchanged puerarin was detected in urine and feces. Pharmacokinetic profiles obtained from this study could help to design the prescribed remedy of puerarin and $P$. mirifica extract phytopharmaceutical products for human use. 


\begin{tabular}{|c|c|}
\hline \multicolumn{2}{|c|}{ ABBREVIATIONS } \\
\hline ADME & $\begin{array}{l}\text { absorption, distribution, metabolism and } \\
\text { excretion }\end{array}$ \\
\hline ALT & alanine aminotransferase \\
\hline AR & accumulation ratio \\
\hline AST & aspartate aminotransferase \\
\hline $\mathrm{AUC}_{0 \text {-inf }}$ & area under the curve from time zero to infinity \\
\hline $\mathrm{AUC}_{0-\mathrm{t}}$ & $\begin{array}{l}\text { area under the curve from time zero to the last } \\
\text { sampling time }\end{array}$ \\
\hline $\mathrm{AUC}_{0 \text {-tau }}$ & $\begin{array}{l}\text { area under the curve within dosing interval } \\
\text { of last dose to first dose }\end{array}$ \\
\hline $\mathrm{AUC}_{0 \text {-tau,ss }}$ & $\begin{array}{l}\text { area under the curve over dosing interval at } \\
\text { steady state of first dose to last dose }\end{array}$ \\
\hline $\mathrm{CL} / \mathrm{F}$ & clearance \\
\hline$C_{\max }$ & maximum plasma concentration \\
\hline IV & intravenous \\
\hline MRT & mean residence time \\
\hline PME & Pueraria mirifica extract \\
\hline PO & per os or oral administration \\
\hline PUE & puerarin \\
\hline $\mathrm{T}_{1 / 2}$ & half-life \\
\hline $\mathrm{T}_{\max }$ & time to reach maximum plasma concentration \\
\hline$V_{d} / F$ & volume of distribution \\
\hline
\end{tabular}

\section{Introduction}

Pueraria candollei var. mirifica (Airy Shaw \& Suvat.) Niyomdham, known in Thai as white Kwao Krua, is an endemic Thai plant belonging to the family Fabaceae [1]. Its tuberous root has long been used as a Thai traditional medicine for rejuvenation, sleep disorder, memory loss, general vigor, and development of the breasts $[2,3]$. Later, it was tested in laboratory animals for its efficacy on tumor incidence [4], bone remodeling [5], and cardiovascular diseases [6]. PME from the roots has minimal toxicity to cardiovascular function, blood lipid levels, and liver enzyme activity in rabbits [6] and menopausal women [7,8]. The major bioactive components of PME are isoflavones [9], with PUE being the main (highest amount) one [4]. PUE ( $\triangleright$ Fig. 1) has several pharmacological effects, such as increasing osteoblast activities [10] and inhibiting osteoclast activities [11], blood clotting [12], and neuronal apoptosis [13], and exhibiting anti-inflammation and antioxidant activities [14]. Moreover, PUE exhibits limited toxicity to cardiovascular function and hematological parameters in rats $[15,16]$. Based on these diverse pharmacological and safety data of PUE and PME, the development of these 2 substances as phytopharmaceutical products for clinical use is planned.

There have been reports on the pharmacokinetics of PUE in various animal species, and interspecies differences in their pharmacokinetic profiles were found [17-19]. The pharmacokinetics of PUE in mice, rats, and dogs fitted a 2-compartment model, while it fitted a 3-compartment model in rabbits [17-19]. The absorption of PUE after a single oral administration also differed among rats, rabbits, and dogs. In rats, PUE was absorbed at $2.10-7.50 \%$ of the given dose $[20,21]$ and reached a $C_{\max }$ at $0.19-1.83 \mathrm{~h}$ [20-23]. In rabbits and dogs, PUE reached the $C_{\max }$

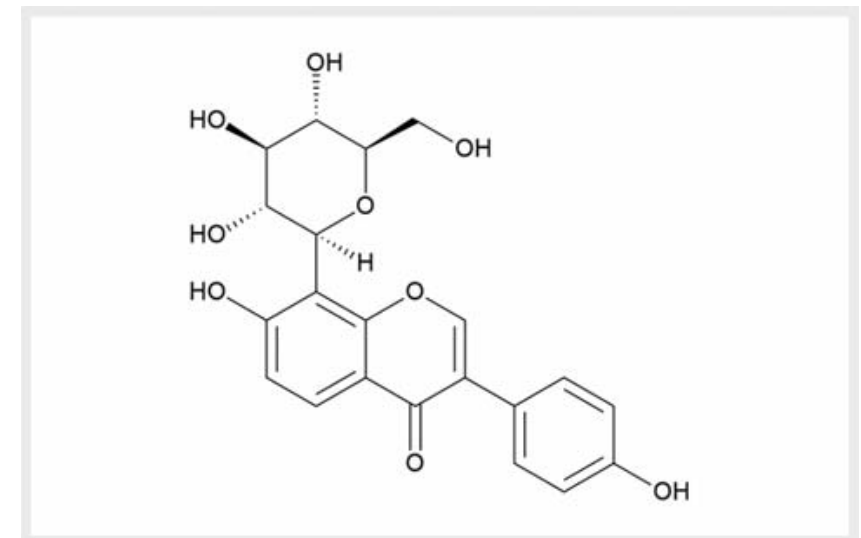

- Fig. 1 Chemical structures of PUE $(M W=416.38 \mathrm{~g} / \mathrm{mol})$ and its derivatives.

at $0.83-1.08 \mathrm{~h}$ [24] and 1.50-4.00 h [25], respectively. After $1 \mathrm{~h}$ of PUE IV administration in rats, PUE was found in the liver, spleen, kidneys, femurs, tibias, mammary glands, lungs, heart, and brain [20]. Moreover, PUE administered to rats could cross the bloodbrain barrier and become widely distributed in many areas of the brain, such as the hippocampus, cerebral cortex, and striatum [26]. The biotransformation of PUE in humans and rats has been reported to occur via multiple reactions [20,27-29]. Phase I hydrolysis and phase II glucuronidation in humans changed PUE into daidzein and PUE glucuronides [27], respectively, while, in rats, the daidzein was further biotransformed by phase I reduction to dihydrodaidzein and finally into equol [28]. Daidzein was also metabolized by phase II (sulfation) to obtain daidzein-sulfate as a final product in rats [29]. For excretion in rats, PUE glucuronides, as the major metabolites of PUE, were mainly excreted via urine and to a lesser extent via feces $[20,28]$.

Although the pharamcokinetic data on PUE are vast, it is still inconclusive because of the contradictory results and the different anatomical and physiological characteristics of those animal models from the humans. If we aim to develop PUE and PME as phytopharmaceutical products for human use, especially for oral dosing, then pharmacokinetic studies of PUE and PME in animals with phenotypes and a gastrointestinal tract that are similar to those of humans should be used, and nonhuman primates are the animals of choice. Among many existing species of nonhuman primates, cynomolgus macaque (Macaca fascicularis) is the most commonly used animal model for pharmacokinetic studies of pharmaceutical products [30]. The gastric $\mathrm{pH}$ and gastric emptying time after fasting in cynomolgus monkeys are 1.9-2.2 and $153 \pm 87$ mins [31], respectively, compared to $\mathrm{pH} 1.5-3.5$ and $248 \pm 39$ mins in humans [32,33], and a gastric $\mathrm{pH}$ of $4-4.3$ and 74 min liquid orocecal transit after fasting in rats [32,34]. Besides, CYP3A, a drug metabolizing enzyme found in the liver, showed $93 \%$ similarity of animo acid sequences between monkeys and humans [35]. Therefore, in this study, we compared the pharmacokinetics of PUE alone and in PME in female cynomolgus monkeys. The PUE and PME (at an equivalent PUE dose of $10 \mathrm{mg} / \mathrm{kg}$ ) were selected based on their efficacy in amelioration of osteoporotic and postmenopausal symptoms in female cynomolgus monkeys [36,37]. 
- Table 1 Plasma levels of AST, ALT, and creatinine before $(0 \mathrm{~h})$ and after $(24 \mathrm{~h})$ single oral dosing (PO) of vehicle (9: 91 [v/v] DMSO: PBS), and after (24 h) single IV of $1 \mathrm{mg} / \mathrm{kg}$ PUE and multiple oral dosing (at day 1 and day 7) of $10 \mathrm{mg} / \mathrm{kg}$ PUE or $826 \mathrm{mg} / \mathrm{kg}$ PME in female cynomolgus monkeys. Data are shown as the mean $\pm S D$ ( $n=4$ for each treatment group).

\begin{tabular}{|l|l|l|l|l|l|l|l|}
\hline $\begin{array}{l}\text { Biochemical } \\
\text { marker }\end{array}$ & Vehicle & PUE-IV & PUE-PO & PME-PO \\
\hline AST (U/L) & $36.54 \pm 7.43^{*}$ & $165.13 \pm 122.16$ & $106.25 \pm 49.00$ & $170.25 \pm 19.87^{\text {a }}$ & $70.63 \pm 25.04$ & $244.63 \pm 110.20^{\text {a }}$ & $67.25 \pm 26.48$ \\
\hline ALT (U/L) & $48.00 \pm 43.98$ & $99.42 \pm 69.83$ & $46.38 \pm 38.14$ & $103.00 \pm 29.11$ & $89.63 \pm 54.06$ & $137.13 \pm 66.81$ & $95.63 \pm 55.76$ \\
\hline $\begin{array}{l}\text { Creatinine } \\
\text { (mg/dL) }\end{array}$ & $0.94 \pm 0.15$ & $0.90 \pm 0.14$ & $0.91 \pm 0.09$ & $0.88 \pm 0.10$ & $0.93 \pm 0.10$ & $0.90 \pm 0.12$ & $0.81 \pm 0.05$ \\
\hline
\end{tabular}

${ }^{*} \mathrm{p}<0.05: 0$ h vs. $24 \mathrm{~h} ;{ }^{\mathrm{a}} \mathrm{p}<0.05$ : day 1 vs. day 7.

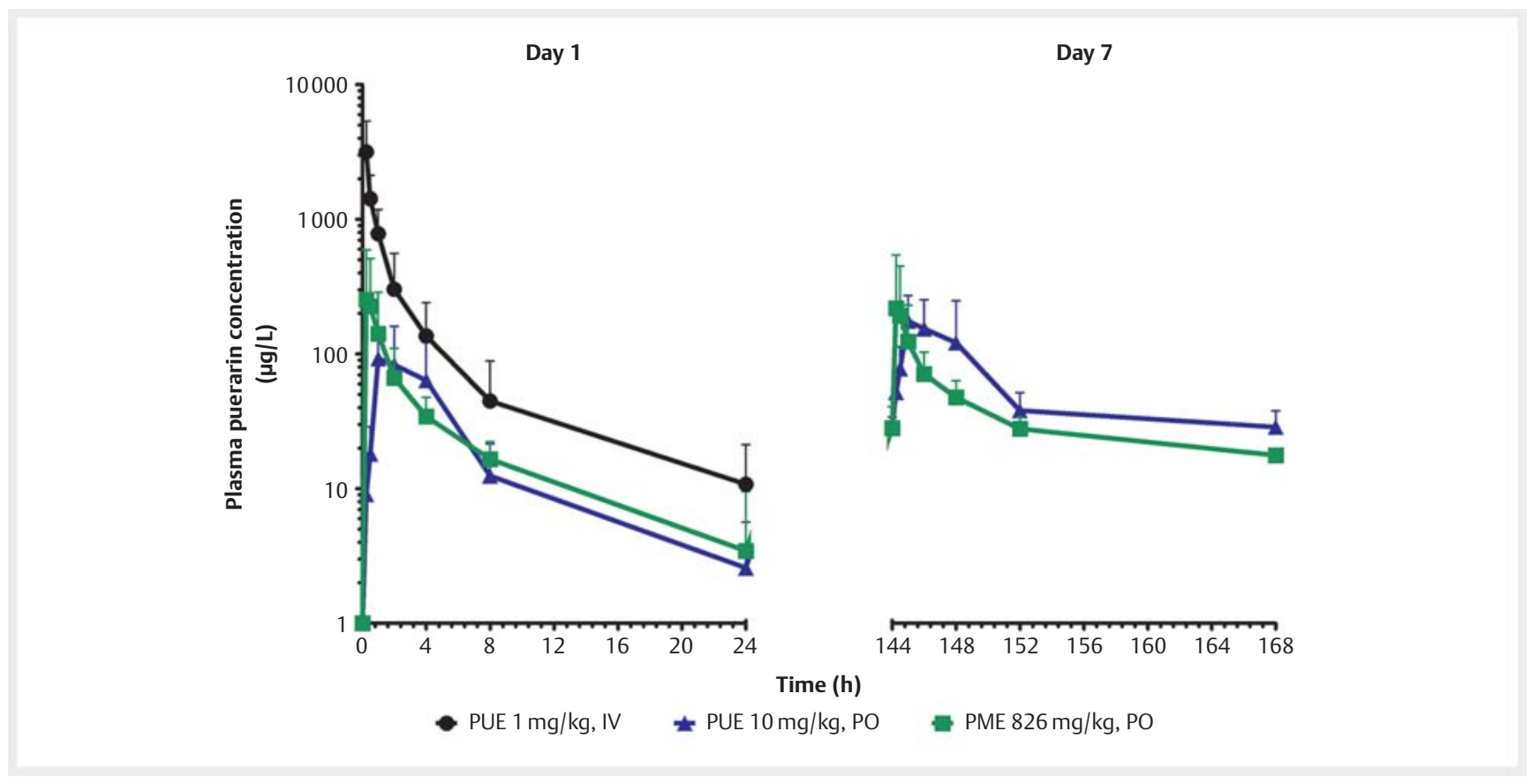

- Fig. 2 Plasma concentration-time profile of PUE after a single IV injection of $1 \mathrm{mg} / \mathrm{kg}$ PUE and a multiple oral dosing (PO; at day 1 and day 7$)$ of $10 \mathrm{mg} / \mathrm{kg}$ PUE and $826 \mathrm{mg} / \mathrm{kg}$ PME in female cynomolgus monkeys. Data are presented as the mean \pm SD $(n=4)$.

\section{Results}

The biochemical markers indicating liver and kidney functions, including AST, ALT, and creatinine levels before $(0 \mathrm{~h})$ and after $(24 \mathrm{~h})$ a single oral administration and after $(24 \mathrm{~h})$ a single IV and multiple oral administrations in all 4 experimental groups are shown in $>$ Table 1. After a single oral administration of the vehicle (single oral dose of 9:91 [v/v] DMSO:PBS) for $24 \mathrm{~h}$, only the AST level was significantly increased. No significant differences between the vehicle control group and the 3 other treatment groups after $24 \mathrm{~h}$ administration for AST, ALT, and creatinine levels were detected. After a single IV of $1 \mathrm{mg} / \mathrm{kg}$ PUE (PUE-IV group) and at day 1 of multiple PO of $10 \mathrm{mg} / \mathrm{kg}$ PUE (PUE-PO group) or $826 \mathrm{mg} / \mathrm{kg}$ PME (PME-PO group), the AST and creatinine levels were not significantly different between the groups, whereas the
ALT levels in both the PUE-PO and PME-PO groups were numerically but not significantly higher than in the PUE-IV group $(p=0.056)$. Comparing between day 1 and day 7 in the PUE-PO and PME-PO groups, the levels of AST significantly decreased at day 7 in both groups, while there were no changes in the ALT and creatinine levels. All 3 biochemical markers had returned to the normal range of adult cynomolgus monkeys at day 7 . Animals in all 4 groups had a normal physical appearance throughout the study period.

Mean plasma concentration-time profiles of PUE after a single IV injection of $1 \mathrm{mg} / \mathrm{kg}$ PUE and multiple PO of $10 \mathrm{mg} / \mathrm{kg}$ PUE or $826 \mathrm{mg} / \mathrm{kg}$ PME (equivalent to $10 \mathrm{mg} / \mathrm{kg}$ PUE) are illustrated in - Fig. 2. For the PUE-IV group, PUE showed a concentration range from $10-10000 \mu \mathrm{g} / \mathrm{L}$ at day 1 during $5 \mathrm{~min}$ to $24 \mathrm{~h}$ after dosing. For the PO groups, monkeys had a 10- to 100 -fold lower level of 
- Table 2 Pharmacokinetic parameters after a single IV injection (IV) of $1 \mathrm{mg} / \mathrm{kg}$ PUE, multiple oral administration (PO; at day 1 and day 7 ) of $10 \mathrm{mg} / \mathrm{kg}$ PUE or $826 \mathrm{mg} / \mathrm{kg}$ PME in female cynomolgus monkeys ( $\mathrm{n}=4$ for each treatment group).

\begin{tabular}{|c|c|c|c|c|c|}
\hline \multirow{2}{*}{$\begin{array}{l}\text { Pharmacokinetic } \\
\text { parameter }\end{array}$} & \multirow[t]{2}{*}{ PUE-IV } & \multicolumn{2}{|l|}{ PUE-PO } & \multicolumn{2}{|l|}{ PME-PO } \\
\hline & & Day 1 & Day 7 & Day 1 & Day 7 \\
\hline$C_{\max ^{a}}(\mu \mathrm{g} / \mathrm{L})$ & N/A & $125.97 \pm 68.68$ & $219.94 \pm 101.61$ & $262.13 \pm 335.70$ & $237.03 \pm 315.62$ \\
\hline $\mathrm{T}_{\max }{ }^{b}(\mathrm{~h})$ & $\mathrm{N} / \mathrm{A}$ & $1.50(1.00 ; 2.50)$ & $1.50(1.00 ; 2.50)$ & $0.25(0.25 ; 0.56)$ & $0.63(0.25 ; 1.50)$ \\
\hline $\mathrm{AUC}_{0-\mathrm{t}^{a}}\left(\mu \mathrm{g}^{*} \mathrm{~h} / \mathrm{L}\right)$ & $6751.86 \pm 9781.80$ & $541.79 \pm 373.67$ & $1376.40 \pm 704.45$ & $648.31 \pm 383.89$ & $893.23 \pm 330.38$ \\
\hline $\mathrm{AUC}_{0 \text {-inf }}{ }^{a}\left(\mu \mathrm{g}^{*} \mathrm{~h} / \mathrm{L}\right)$ & $6751.86 \pm 9781.80$ & $595.67 \pm 384.85^{*}$ & $3138.73 \pm 1035.35^{\dagger}$ & $975.06 \pm 656.42$ & $1658.74 \pm 377.32$ \\
\hline $\mathrm{MRT}^{b}(\mathrm{~h})$ & $0.46(0.24 ; 1.08)$ & $6.03(4.03 ; 13.19)^{*}$ & $45.69(42.89 ; 36.12)$ & $4.32(2.94 ; 69.87)$ & $39.40(19.78 ; 30.53)$ \\
\hline $\mathrm{V}_{\mathrm{d}} / \mathrm{F}^{a}(\mathrm{~L} / \mathrm{kg})$ & $0.47 \pm 0.34$ & $231.70 \pm 333.87$ & $222.55 \pm 99.85$ & $171.12 \pm 275.37$ & $258.49 \pm 93.90$ \\
\hline $\mathrm{CL} / \mathrm{F}^{a}(\mathrm{~L} / \mathrm{h} / \mathrm{kg})$ & $0.44 \pm 0.31$ & $26.99 \pm 23.75$ & $3.42 \pm 0.96^{\dagger}$ & $15.58 \pm 11.62$ & $6.25 \pm 1.28$ \\
\hline $\mathrm{T}_{1 / 2^{b}}(\mathrm{~h})$ & $0.71(0.66 ; 0.11)$ & $4.78(0.69 ; 17.64)^{*}$ & $37.96(35.83 ; 25.15)$ & $2.61(0.66 ; 54.63)$ & $34.33(18.49 ; 17.57)$ \\
\hline Bioavailability (\%) & $\mathrm{N} / \mathrm{A}$ & 0.88 & $\mathrm{~N} / \mathrm{A}$ & 1.44 & $\mathrm{~N} / \mathrm{A}$ \\
\hline $\mathrm{AR}^{a}$ & & $3.19 \pm 1.45$ & & $1.94 \pm 1.57$ & \\
\hline \multicolumn{6}{|c|}{$\begin{array}{l}\text { Notes: }{ }^{\text {a }} \text { Data are shown as mean } \pm \mathrm{SD}(\mathrm{n}=4) .{ }^{\mathrm{b}} \text { Data are shown as median }\left(\mathrm{P}_{25} ; \mathrm{P}_{75}\right) ;{ }^{*} \mathrm{P}<0.05 \text { : day } 1 \text { vs day } 7 ;{ }^{\dagger} \mathrm{P}<0.05: \mathrm{PUE}-\mathrm{PO} \text { vs. PME-PO at Day } 7 . \\
\text { Abbreviations: } \mathrm{C}_{\max } \text { : maximum concentration; } \mathrm{T}_{\text {max }} \text { : time to reach maximum concentration; } A \cup C_{0-\mathrm{t}} \text { : area under concentration-time curve from time } 0 \\
\text { to last observed time; } A U C_{0 \text {-inf: }} \text { area under concentration-time curve from time } 0 \text { to infinity; } \mathrm{V}_{\mathrm{d}} / \mathrm{F} \text { : apparent volume of distribution; MRT: mean residence } \\
\text { time; } \mathrm{T}_{1 / 2} \text { : half-life; } \mathrm{CL} / \mathrm{F} \text { : apparent clearance; AR: accumulation ratio; } \mathrm{N} / \mathrm{A} \text { : not available. }\end{array}$} \\
\hline
\end{tabular}

PUE than the IV group, even though the PO dose was 10-fold higher than the IV dose. Interestingly, the PME-PO group exhibited a shorter time to reach the $T_{\max }$ and at a higher $C_{\max }$ than the PUE-PO group during $24 \mathrm{~h}$. Multiple daily oral dosing with either the PUE-PO or PME-PO resulted in higher PUE levels at day 7 than at day 1 (after a single oral dosing).

The pharmacokinetic parameters of PUE were determined using noncompartmental analysis and are summarized in $>$ Table 2. Absolute bioavailability of PUE as a pure compound (PUE-PO group) was $0.88 \%$ and in PME (PME-PO group) was $1.44 \%$ after a single oral dose (day 1 ). The AR after multiple oral dosing for 7 days of PUE alone was higher than the PME (3.19 vs. 1.94). The MRT of PUE in both oral groups was higher on day 7 (39-46 h) than on day 1 (4-6h). Similarly, elimination half-lives of PUE in both groups were also longer on day 7 (34-38 h) than on day 1 (3-5 h). No significant differences of all pharmacokinetic parameters between day 1 of PUE-PO and PME-PO groups were detected, but the clearance rate at day 7 of the PUE-PO group was significantly lower than the PME-PO group.

According to metabolite identification, performed by QTOF LCMS analysis, 2 major metabolites were found after IV and PO dosing in female cynomolgus monkeys ( $\bullet$ Fig. 3 ). The hydroxylation product of PUE was detected at a MW of $432.38 \mathrm{~g} / \mathrm{mol}$ and a retention time of $28.85 \mathrm{~min}$. In addition, the deglycosylation product of PUE, known as daidzein (MW $254.06 \mathrm{~g} / \mathrm{mol}$ and a retention time of $15.45 \mathrm{~min}$ ), was found in the plasma, urine, and feces of the monkey. A negligible amount of unchanged PUE was detected in the excreta at 24 and $48 \mathrm{~h}$ after administration of a single IV dose or after multiple PO at both day 1 and day 7 ( $\bullet$ Table 3).

\section{Discussion}

Comparative pharmacokinetics of PUE and PME, at an equivalent PUE dose of $10 \mathrm{mg} / \mathrm{kg}$, after oral dosing for 7 consecutive days was conducted to elucidate the pharmacokinetic profiles of PUE in 2 preparations. Cynomolgus monkeys were selected as animal models for this study because the interspecies differences between rats and humans, based upon a previous report [20], needs to be addressed before it can be applied for human use. The pharmacokinetics were analyzed at day 1 , which counted as a single oral dose, and at day 7 , which was considered as multiple oral dosing. The results at day 1 were also compared with that of a single IV injection of $1 \mathrm{mg} / \mathrm{kg}$ PUE to evaluate the oral bioavailability.

All female monkeys did not show any abnormal physical appearance or abnormal liver and kidney functions after multiple oral dosing. Constant levels of a plasma kidney marker (creatinine) were in line with those reported in cynomolgus monkeys [38] and humans [39]. A significant elevation of plasma AST level, a liver marker, at $24 \mathrm{~h}$ after oral dosing of the vehicle was assumed to indicate the stress effect on animal manipulations during the experiment. Indeed, similar conditions were observed previously in healthy rhesus monkeys ( $M$. mulatta) after oral dosing of normal saline [40]. Thus, a significant decrease in plasma AST levels on day 7 , compared to day 1 , of PUE and PME administration indicated that the animals had adapted to the experimental condition.

The administration of PME showed a slightly higher oral bioavailability than the PUE after a single oral dose in cynomolgus monkeys. This phenomenon might be explained by the fact that PME is a mixture of several compounds from the tuberous root of $P$. mirifica, which contains bioenhancers and can inhibit both the efflux transporters and drug metabolizing enzymes at the brush border membrane of the small intestine. Therefore, superior absorption parameters (higher $C_{\max }$ and shorter $T_{\max }$ ) were ob- 
<smiles>O=c1c(-c2ccc(O)cc2)coc2c([C@]3(O)O[C@H](CO)[C@@H](O)[C@H]3O)c(O)ccc12</smiles>

Puerarin; MW $416.38 \mathrm{~g} / \mathrm{mol} ; \mathrm{m} / \mathrm{z} 415.10$; RT: 15.95 min; Formula: $\mathrm{C}_{21} \mathrm{H}_{20} \mathrm{O}_{9}$
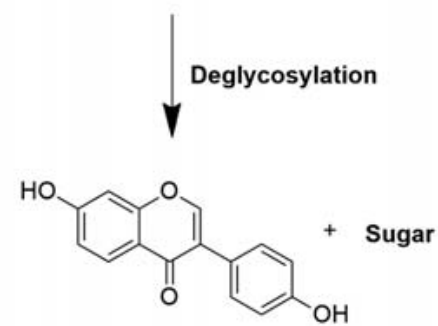

Daidzein; MW $254.06 \mathrm{~g} / \mathrm{mol} ; \mathrm{m} / \mathrm{z} 253.00$; RT: $15.45 \mathrm{~min}$; Formula: $\mathrm{C}_{15} \mathrm{H}_{10} \mathrm{O}_{4}$<smiles>O=c1c(-c2ccc(O)c(O)c2)coc2c(O)ccc(O)c12</smiles>

Hydroxylation; MW $432.38 \mathrm{~g} / \mathrm{mol} ; \mathrm{m} / \mathrm{z} 431.10$; RT: 28.85 min; Formula: $\mathrm{C}_{21} \mathrm{H}_{20} \mathrm{O}_{10}$

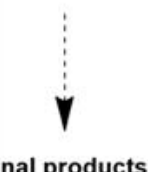

Final products

- Fig. 3 Proposed metabolic pathway of PUE in female cynomolgus monkeys.

- Table 3 Percent recovery of PUE in the urine and feces of female cynomolgus monkeys after a single IV injection of $1 \mathrm{mg} / \mathrm{kg}$ PUE, multiple oral administration (PO; at day 1 and day 7) of $10 \mathrm{mg} / \mathrm{kg}$ PUE or $826 \mathrm{mg} / \mathrm{kg}$ PME. Data are shown as the mean \pm SD $(n=4)$.

\begin{tabular}{|c|c|c|c|c|c|}
\hline Percent recovery & PUE-IV & PUE-PO & PME-PO & Day 7 \\
\hline & & Day 1 & Day 7 & Day 1 & $<1.00$ \\
\hline Urine & & & & $<1.00$ \\
\hline $0-24 \mathrm{~h}$ & $<1.00$ & $<1.00$ & $<1.00$ & $<1.00$ & \\
\hline $24-48 \mathrm{~h}$ & $<1.00$ & $<1.00$ & $<1.00$ & $<1.00$ & $1.91 \pm 1.74$ \\
\hline Feces & & & & $1.30 \pm 1.60$ & $<1.00$ \\
\hline $0-24 \mathrm{~h}$ & $<1.00$ & $<1.00$ & $<1.00$ & $<1.00$ & \\
\hline $24-48 \mathrm{~h}$ & $<1.00$ & $<1.00$ & $<1.00$ & & \\
\hline
\end{tabular}

served in the PME group compared to PUE alone. The oral bioavailability of PUE in nonhuman primates was lower than that previously reported in rodents (1.0 vs. $7.0 \%)$ [20]. One possible explanation is that the small intestine of cynomolgus monkey had a lower membrane permeability than those in rats [41]. In accord, a previous study demonstrated that the bioavailability of a single oral dose of piroxicam, a nonsteroid anti-inflammatory drug, in rats was higher than that in cynomolgus macaques [42].

Note that multiple oral dosing of PUE and PME showed a similar tendency for systemic accumulation, with an AR of 1.94-3.19. The MRT, which is a summation of the ADME process, increased approximately 7- to 9-fold after multiple oral dosing in both groups. This phenomenon correlated well with the excretion parameters, with lower clearance and longer elimination half-life being observed on day 7. It was previously reported that the $\mathrm{AUC}_{0 \text {-inf }}$ for oral dosing of PME in humans after 3 consecutive days, 3 times a day, was higher than after a single dose and had a steady-state concentration of $40.98 \mu \mathrm{g} / \mathrm{L}$ [39]. Since 2 preparations of PUE were given to monkeys in this study, in PME and as PUE alone, the drug-drug interaction and drug metabolizing reaction that affect the bioavailability should be different between these 2 preparations. The drug-drug interaction and drug metabolizing reaction should occur after multiple dosing of PME, while the drug metabolizing reaction should mainly be observed in the 
PUE-alone preparation. Drug metabolizing reaction was reported in the PUE treated rats. It was shown that PUE inhibits the activity of P-gp or CYP3A4 [43]. P-gp is an ATP-dependent transmembrane efflux pump that is expressed in columnar epithelial cells of the lower gastrointestinal tract and canalicular surface of hepatocytes [44]. CYP3A4 is the most abundant cytochrome P450 presented in human hepatocytes and intestinal enterocytes [45, 46]. PME contains at least 17 phytoestrogenic substances [1]; drugdrug interaction can occur via bioenhancement or efflux transporter activity [47] as mentioned earlier. Thus, multiple oral dosing of PUE and PME caused the 3- to 5-fold lower clearance rate and longer $T_{1 / 2}$. Accordingly, multiple dosing of PUE and PME could improve metabolic exposure and should result in better pharmacological outcomes in nonhuman primates as well as in humans.

Glucuronidation is reported to be the major reaction pathway in the biotransformation of PUE in rats and humans [20,48]. However, we found that hydroxylation and deglycosylation were the 2 major biotransformations of PUE in female cynomolgus monkeys. Indeed, hydroxylated PUE and daidzein were the 2 major metabolites found in the plasma after IV and oral dosing of PUE and PME. The hydoxylated PUE was also reported in rats and detected in the urine in a $0-4 \mathrm{~h}$ period [28]. Since the intestinal bioavailability ( $\left.\mathrm{Fl}=\mathrm{F} /\left[\mathrm{FH}^{*} \mathrm{Fa}\right]\right)$ in female cynomolgus monkeys is very low (about 0.012 or $1.2 \%$ ), this suggests that the intestine plays a major role in the metabolism of PUE. The plausible enzymes in intestinal enterocytes metabolizing the PUE are P-gP and CYP3A [43]. PUE was reported as a plausible substrate of P-gp [47]. In monkeys, CYP3A4 might induce hydroxylation and produce hydroxylated PUE [45]. CYP3A may also hydrolyze PUE to daidzein. Interspecies differences in the metabolic pathway of PUE and the enzyme(s) responsible for these biochemical reactions might need further exploration. Only negligible amounts of unchanged PUE was found in the excreta of cynomolgus monkeys after dosing with PUE or PME for $48 \mathrm{~h}$, and so most of the PUE was biotransformed into other products before excretion.

\section{Materials and Methods}

\section{Chemicals and plant materials}

The PUE powder (99.0\% purity) was purchased from Pure Chemistry Scientific, while $P$. mirifica tuberous root powder (Lot no. 141023 ) was provided by Smith Natural. The $P$. mirifica powder was extracted using $95 \%(\mathrm{v} / \mathrm{v})$ ethanol in a Soxhlet extractor at $60^{\circ} \mathrm{C}$ for $6 \mathrm{~h}$, filtered through Whatman no. 4 filter paper, and dried by a rotary evaporator at $60^{\circ} \mathrm{C}$. The obtained PME was prepared and stored in a dark bottle at $4{ }^{\circ} \mathrm{C}$ until used in the pharmacokinetic study, while a portion was used for analysis of the PUE content by LCMS analysis. The PUE content was $1.21 \mathrm{mg} / 100 \mathrm{mg}$ of PME. The DMSO (purity $>99.5 \%$ ), ethanol (purity $>95.0 \%$ ), and PBS were purchased from Sigma-Aldrich. Glycyrrhetinic acid (purity $>90.0 \%$ ), as an internal standard, was acquired from Wako Pure Chemical Industries. HPLC-grade methanol (100.0\% purity) was acquired from Merck.

\section{Preparation of PUE and PME solution}

The PUE and PME were freshly prepared by dissolving in DMSO until a clear solution and then diluted with PBS $(\mathrm{pH} 7.4)$ and mixed to obtain a clear PUE or PME solution of the desired concentration in 9:91 (v/v) DMSO: PBS. To compare the pharmacokinetics of PUE alone and in PME after oral dosing, the dosage of PME was adjusted to $826 \mathrm{mg} / \mathrm{kg}$, equivalent to $10 \mathrm{mg} / \mathrm{kg}$ of PUE. In addition, PUE at a dose of $1 \mathrm{mg} / \mathrm{kg}$ was used for IV administration. Each test substance solution was aseptically filtered using a $0.22-\mu \mathrm{m}$ pore size polytetrafluoroethylene syringe filter.

\section{Animal subjects}

Sixteen adult female cynomolgus monkeys, aged 5- to 7-y-old and with a body weight of $3.5-5.0 \mathrm{~kg}$, were supplied by the Breeding Facility of the National Primate Research Center of Thailand-Chulalongkorn University (NPRCT-CU). The female monkeys were selected for the study due to the ease in handling for oral administration of the test items under nonanesthetized condition. They were individually housed in stainless-steel cages with controlled lighting ( $12 \mathrm{~h}$ of dark-light cycle, light on from $6 \mathrm{a}$. m. to $6 \mathrm{p} . \mathrm{m}$.) at $25 \pm 1^{\circ} \mathrm{C}$ and $50 \pm 10 \%$ relative humidity at the Animal Biosafety Level- 1 facility of the NPRCT-CU, Thailand. The facility has been AAALAC International accredited. The animals were fed with standard monkey chow diet (Perfect Companion Group Co., Ltd.) in the morning (09:00-10:00 h) and fresh fruits and vegetables in the afternoon (14:00-15:00 h), with free access to hyperchlorinated water $\mathrm{pH}$ 7.3-7.7. To ensure the complete absorption of the test items, however, monkeys were fasted for at least $4 \mathrm{~h}$ after each time of the test item administration [31]. The experimental protocol was approved by the Institutional Animal Care and Use Committee of the NPRCT-CU (Protocol review number: 1975005; Approval date: April 17, 2019). During the study, the monkeys were clinically observed daily by a veterinary technician and a veterinarian.

Animals were randomized and divided into 4 groups ( $n=4$ per group) and administered a single IV injection of PUE at $1 \mathrm{mg} / \mathrm{kg}$, a single oral vehicle (9:91 [v/v] DMSO: PBS), and multiple oral PUE at $10 \mathrm{mg} / \mathrm{kg}$ or PME at $826 \mathrm{mg} / \mathrm{kg}$ (equivalent to $10 \mathrm{mg} / \mathrm{kg}$ of PUE), respectively. In the multiple-oral dosing groups, PUE or PME was administered daily for 7 consecutive days.

\section{Pharmacokinetics study}

For the IV group, blood samples ( $1 \mathrm{~mL}$ each) were collected at 0 (pre-dose), $5 \mathrm{~min}$, and $0.25,0.5,1,2,4,8$, and $24 \mathrm{~h}$ after dosing. For the oral group, serial blood samples were collected at 0 (predose), $0.25,0.5,1,2,4,8$, and $24 \mathrm{~h}$ after dosing on day 1 and then day 7. Blood samples were collected in a heparinized tube and centrifuged at $1700 \mathrm{~g}$ at $4^{\circ} \mathrm{C}$ for $20 \mathrm{~min}$. The obtained plasma was harvested and kept at $-20^{\circ} \mathrm{C}$ until analysis of PUE and its metabolites. Urine and fecal samples were collected at 2 periods: at $0-24 \mathrm{~h}$ and $24-48 \mathrm{~h}$ after dosing (on day 1 of single IV dosing and on day 1 and day 7 of multiple oral dosing). Excreta were homogenized and centrifuged at $5000 \mathrm{~g}$ at $4^{\circ} \mathrm{C}$ for $20 \mathrm{~min}$. The supernatant was then isolated and kept at $-20^{\circ} \mathrm{C}$ until analyzed for pharmacokinetics and identification of PUE metabolites by LCMS. 


\section{Blood chemistry analysis}

Additional blood samples $(2 \mathrm{~mL})$ were collected from femoral vein of each animal at $0 \mathrm{~h}$ (on day 1 of single PO dosing of vehicle only) and $24 \mathrm{~h}$ (on day 1 of single PO and IV dosing, and on day 1 and day 7 of multiple oral dosing) after administration of the respective test substances. Blood plasma $(500 \mu \mathrm{L})$ was separated as explained above in the pharmacokinetics study and analyzed for plasma AST, ALT, and creatinine levels using a Sysmex BX-3010 automated biochemistry analyzer (Furuno electric).

\section{Bioanalysis of PUE and its metabolites in biological specimens}

Plasma, urine, and feces specimens were collected and then treated by the protein precipitation method [28]. In brief, $50 \mu \mathrm{L}$ of each sample was mixed with $200 \mu \mathrm{L}$ of methanol containing $100 \mathrm{ng}$ glycyrrhetinic acid (as an internal standard) and vortexed for $10 \mathrm{~min}$. The mixture was then centrifuged at $12000 \mathrm{~g}$ at $4^{\circ} \mathrm{C}$ for $10 \mathrm{~min}$, and $150 \mu \mathrm{L}$ of supernatant was collected to determine the concentration of PUE and its metabolites by LCMS. The internal standard, and PUE at concentrations of 1000, 500, 250, 125, 62.5, $31.25,15.625,7.8125$, and $3.90625 \mathrm{ng} / \mathrm{mL}$ were spiked in the blank matrices (plasma, urine, and feces) and the different standard curves were constructed to measure the concentration of PUE in each biological specimen.

The LCMS system was run on a Shimadzu LCMS 8060, equipped with a vacuum degasser, a binary pump, an autosampler, and a triple quadrupole LCMS with an electrospray ionization (ESI) source, operated and controlled by LabSolution version 5.86 software (Shimadzu). The Nexera Ultra-High-Performance LC system was equipped with C18 column, Phenomenex Synergi Fusion-RP, with an oven temperature of $40^{\circ} \mathrm{C}$. The mobile phase was $100 \%$ $(\mathrm{v} / \mathrm{v})$ methanol and $0.2 \%(\mathrm{v} / \mathrm{v})$ formic acid in water $(\mathrm{pH} 2.5)$, at a flow rate of $0.5 \mathrm{~mL} / \mathrm{min}$, run as a gradient starting at $10 \%(\mathrm{v} / \mathrm{v})$ methanol for $1.5 \mathrm{~min}$, increased to $90 \%(\mathrm{v} / \mathrm{v})$ methanol at 1.5 to $3.5 \mathrm{~min}$, and then decreased to $10 \%(\mathrm{v} / \mathrm{v})$ methanol at 4 to $4.5 \mathrm{~min}$. The MS analysis was operated in a negative ionization mode by monitoring precursor ion to product ion transitions with mass to charge ratios of 415.05/267.00 (PUE) and 469.35/409.40 (glycyrrhetinic acid). Retention times of PUE and glycyrrhetinic acid were 1.46 , and $2.09 \mathrm{~min}$, respectively. Calibration curves of PUE presented a good linearity range from $5-1000 \mu \mathrm{g} / \mathrm{L}$ $\left(R^{2}>0.99\right)$. The limit of detection was estimated to be $1 \mu \mathrm{g} / \mathrm{L}$ with a signal-to-noise ratio of 5 . The intra- and inter-assay accuracy was within $\pm 10 \%$. The analysis showed good specificity that there was no other impurity interference around the retention times of the target compound and internal standard. The recovery of the quality control samples was between $80-98 \%$, and the stability during the procedure and storage remained stable.

For metabolite identification, the experiment was analyzed using an Agilent mass spectrometer 6540 QTOF equipped with liquid chromatograph 1260 (Agilent technologies). The stationary phase was Phenomenex Luna C18 column, and the mobile phase was methanol and $0.2 \%(\mathrm{v} / \mathrm{v})$ formic acid in water, run at a flow rate of $0.5 \mathrm{~mL} / \mathrm{min}$ with gradient elution from $5 \%(\mathrm{v} / \mathrm{v})$ methanol to $95 \%(\mathrm{v} / \mathrm{v})$ methanol within $30 \mathrm{~min}$, and then maintained until 40 min. Column oven was kept constant at $35^{\circ} \mathrm{C}$, and injection volume was $5 \mu \mathrm{L}$ per sample. The MS analysis was conducted in negative mode with ESI. Mass spectra were screened from 100$1000 \mathrm{~m} / \mathrm{z}$, and chromatogram analysis was conducted by Mass Hunter B.06.00 (Agilent Technologies).

\section{Pharmacokinetic and statistical analysis}

Pharmacokinetic analysis was performed using a noncompartmental method with the PK solutions software version 2.0 (Summit Research Services). The $C_{\max }$ and $T_{\max }$ were determined directly from the plasma concentration-time profile. The $\mathrm{AUC}_{0-\mathrm{t}}$ was calculated using the trapezoidal rule, and $A U C_{t-i n f}$ was calculated as $C_{t} / k_{e l}$, where $C_{t}$ was the last observed plasma concentration after administration and $k_{\mathrm{el}}$ is the elimination rate constant, calculated from the slope of the terminal phase of the plasma concentration time curve. The terminal elimination $\mathrm{T}_{1 / 2}$ was calculated as $0.693 / k_{e l}$, where the $k_{e l}$ was the apparent elimination rate constant of PUE from plasma. CL/F was the apparent total clearance and $\mathrm{Vd} / \mathrm{F}$ was the apparent volume of distribution. The ap-

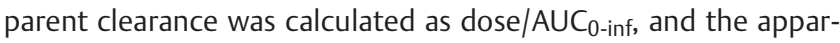
ent volume of distribution was equal to $(C L / F) / k_{\mathrm{e}}$. The MRT was calculated using trapezoid area calculations extrapolated to infinity, as equal to $A \cup M C_{0 \text {-inf }} / \mathrm{AUC}_{0 \text {-inf. }}$ The absolute oral bioavailability (F) was calculated as (mean $\mathrm{AUC}_{0 \text {-inf }}$ of $\mathrm{PO} /$ mean $\mathrm{AUC}_{0 \text {-inf }}$ of IV) $\times$ $($ dose IV/dose PO) $\times 100$. In the multiple dosing, the AR was calculated as the ratio of $A \cup C_{0 \text {-tau,ss }}$ on day 7 to $A \cup C_{0 \text {-tau }}$ on day 1 , where tau is the dosing interval $(24 \mathrm{~h})$ and the AUC values were calculated by the mixed log-linear trapezoidal summations.

All statistical tests were conducted using the SPSS for Window Software (version 22.0). Data are presented as mean \pm 1 standard deviation (SD) or the median with $25-75 \%$ interquartile range. Nonparametric tests were used to determine the significance among groups, accepting significance at the $p<0.05$ level.

\section{Contributors' Statement}

Conception and design of the work: S. Namken, P. Khemawoot, S. Malaivijitnond; data collection: S. Namken, P. Songvut, N. Nuengchamnong, T. Kemthong; analysis and interpretation of the data: S. Namken, P. Khemawoot, S. Malaivijitnond; statistical analysis: S. Namken, P. Khemawoot; drafting the manuscript: S. Namken, P. Khemawoot, S. Malaivijitnond; critical revision of the manuscript: S. Namken, S. Malaivijitnond.

\section{Acknowledgements}

This study was supported by a Scholarship from the Graduate School, Chulalongkorn University to commemorate the 72nd Anniversary of his Majesty King Bhumibol Adulyadej given to SN, the 90th Anniversary Chulalongkorn University Fund (Ratchadaphiseksomphot Endowment Fund), the NPRCT-CU, and the Chulalongkorn University Research Unit Grant given to SM. We would like to thank all staff members of the NPRCT-CU, Saraburi, Thailand, especially Nutchanat Suttisan, Nopparat Kongsombat, Chunapa Linchekhaw, and Chanatip Kraitat, for facility and assistance in the experiment and animal care and use.

\section{Conflict of Interest}

The authors declare that they have no conflict of interest. 


\section{References}

[1] Inham JL, Tahara S, Pope GS. Chemical Components and Pharmacology of the rejuvenating Plant Pueraria mirifica. In: Keung WM, ed. Pueraria: The Genus Pueraria. London: Taylor \& Francis; 2002; 97-118

[2] Kerr A. A reputed rejuvenator. J Siam Soc 1932; 8: 336-338

[3] Wanandorn PW. A reputed rejuvenator. J Siam Soc 1933; 9: 145-147

[4] Cherdshewasart W, Panriansaen R, Picha P. Pretreatment with phytoestrogen-rich plant decreases breast tumor incidence and exhibits lower profile of mammary ER $\alpha$ and ER $\beta$. Maturitas 2007; 58: 174-181

[5] Suthon S, Jaroenporn S, Charoenphandhu N, Suntornsaratoon P, Malaivijitnond S. Anti-osteoporotic effects of Pueraria candollei var. mirifica on bone mineral density and histomorphometry in estrogen-deficient rats. J Nat Med 2016; 70: 225-233

[6] Wattanapitayakul SK, Chularojmontri L, Srichirat S. Effects of Pueraria mirifica on vascular function of ovariectomized rabbits. J Med Assoc Thai 2005; 88: S21-29

[7] Muangman V, Cherdshewasart W. Clinical trial of the phytoestrogenrich herb, Pueraria mirifica as a crude drug in the treatment of symptoms in menopausal women. Siriraj Hosp Gaz 2001; 53: 300-310

[8] Chandeying V, Sangthawan M. Efficacy comparison of Pueraria mirifica against conjugated equine estrogen with/without medroxyprogesterone acetate in the treatment of climacteric symptoms in perimenopausal women: phase III study. J Med Assoc Thai 2007; 90: 1720-1726

[9] Chansakaow S, Ishikawa T, Sekine K, Okada M, Higuchi Y, Kudo M, Chaichantipyuth C. Isoflavonoids from Pueraria mirifica and their estrogenic activity. Planta Med 2000; 66: 572-575

[10] Wang Y, Wang WL, Xie WL, Li LZ, Sun J, Sun WJ, Gong HY. Puerarin stimulates proliferation and differentiation and protects against cell death in human osteoblastic MG-63 cells via ER-dependent MEK/ERK and PI3K/ Akt activation. Phytomedicine 2013; 20: 787-796

[11] Li B, Yu S. Effect of puerarin on the bone metabolism in vitro. Beijing Da Xue Xue Bai 2003; 35: 74-77

[12] Coull BM, William LS, Goldstein LB, Meschai JF, Heitzman D, Chuturvedi S, Chaturvedi KC, Johnston S, Starkman LB, Morgenstern JL, Wilterdink SR, Levine JL. Anticoagulants and antiplatelet agents in acute ischemic stroke. Neurology 2002; 59: 13-22

[13] Zhang H, Liu Y, Lao M, Ma Z, Yi X. Puerarin protects Alzheimer's disease neuronal cybrids from oxidant-stress induced apoptosis by inhibiting pro-death signaling pathways. Exp Gerontol 2011; 46: 30-37

[14] Jin S, Son Y, Min BS, Jung H, Choi J. Anti-inflammatory and antioxidant activities of constituents isolated from Pueraria lobata roots. Arch Pharm Res 2012; 35: 823-837

[15] Zhang S, Shen S, Shen Y, Yang D, Liu X, Sun-Chi AC, Xu H. Puerarin induces angiogenesis in myocardium of rat with myocardial infarction. Biol Pharm Bull 2006; 29: 945-950

[16] Chung HJ, Chung MJ, Houng SJ, Jeun J, Kweon DK, Chung HC, Park JT, Park KH, Lee SJ. Toxicological evaluation of the isoflavone puerarin and its glycosides. Eur Food Res Technol 2009; 230: 145-153

[17] Jin XL, Zhu XY. Pharmacokinetics of puerarin in rats, rabbits, and dogs. Zhongguo Yao Li Xue Bao 1992; 13: 284-288

[18] Yang R, Wang Q, Zeng H, Qin Z, Li J, Qu L. Determination of puerarin in biological samples and its application to a pharmacokinetic study by flow-injection chemiluminescence. Luminescence 2011; 26: 368-373

[19] Ouyang Z, Zhao M, Tang J, Pan L. In vivo pharmacokinetic comparisons of ferulic acid and puerarin after oral administration of monomer, medicinal substance aqueous extract and Nao-De-Sheng to rats. Pharmacogn Mag 2012; 8: 256-262

[20] Anukunwithaya T, Poo P, Hunsakunachai N, Rodsiri R, Malaivijitnond S, Khemawoot P. Absolute oral bioavailability and disposition kinetics of puerarin in female rats. BMC Pharmacol Toxicol 2018; 19: 25-33
[21] Su HF, Lin Q, Wang XY, Fu Y, Gong T, Sun X, Zhang R. Absorptive interactions of concurrent oral administration of (+)-catechin and puerarin in rats and the underlying mechanisms. Acta Harmacol Sin 2016; 37: 545554

[22] Li Y, Pan WS, Chen SL, Xu HX, Yang DJ, Chan ASC. Pharmacokinetic, tissue distribution, and excretion of puerarin and puerarin-phospholipid complex in rats. Drug Dev Ind Pharm 2006; 32: 413-422

[23] Cao L, Pu J, Cao QR, Chen BW, Lee B], Cui JH. Pharmacokinetics of puerarin in pregnant rats at different stages of gestation after oral administration. Fitoterapia 2013; 86: 202-207

[24] Cui S, Zhao C, Tang X, Chen D, He Z. Study on the bioavailability of puerarin from Pueraria lobata isoflavone self-microemulsifying drug-delivery systems and tablets in rabbits by liquid chromatography mass spectrometry. Biomed Chromatogr 2005; 19: 375-378

[25] Ren F, Jing Q, Shen Y, Ma H, Cui J. Quantitative determination of puerarin in dog plasma by HPLC and study on the relative bioavailability of sustained release tablets. J Pharm Biomed Anal 2006; 41: 549-553

[26] Kong H, Zhang G, Cheng J, Shi R, Zhang M, Cao P, Zhao Y, Qu H, Wang Q. Distribution kinetics of puerarin in rat hippocampus after acute local cerebral ischemia. J Pharm Biomed Anal 2019; 164: 196-201

[27] Jung HR, Kim SJ, Ham SH, Cho JH, Lee YB, Cho HY. Simultaneous determination of puerarin and its active metabolite in human plasma by UPLC-MS/MS: application to a pharmacokinetic study. J Chromatogr B Analyt Technol Biomed Life Sci 2014; 971: 64-71

[28] Prasain JK, Jones K, Brissie N, Moore R, Wyss JM, Barnes S. Identification of puerarin and its metabolites in rats by liquid chromatography-tandem mass spectrometry. J Agric Food Chem 2004; 52: 3708-3712

[29] Yasuda T, Kano Y, Saito K, Ohsawa K. Urinary and biliary metabolites of puerarin in rats. Biol Pharm Bull 1995; 18: 300-303

[30] Cauvin AJ, Peters C, Brennan FT. Advantages and Limitations of commonly used nonhuman Primate Species in Research and Development of Biopharmaceuticals. In: Bluemel J, Korte S, Schenck E, Weinbauer GF, eds. The nonhuman Primate in nonclinical Drug Development and Safety Assessment. London: Academic Press; 2015: 379-395

[31] Chen EP, Doan KMM, Portelli S, Coatney R, Vaden V, Shi W. Gastric pH and gastric residence time in fasted and fed conscious cynomolgus monkeys using the Bravo ${ }^{\circledR} \mathrm{pH}$ system. Pharm Res 2008; 25: 123-134

[32] Schwarz R, Kaspar A, Seelig J, Kunnecke B. Gastrointestinal transit times in mice and humans measured with $27 \mathrm{Al}$ and $19 \mathrm{~F}$ nuclear magnetic resonance. Magn Reson Med 2002; 48: 255-261

[33] Bolondi L, Bortolotti M, Santi V, Calletti T, Gaiani S, Labo G. Measurement of gastric emptying time by real-time ultrasonography. Gastroenterol 1985; 89: 752-759

[34] Ward FW, Coates ME. Gastrointestinal pH measurement in rats: influence of the microbial flora, diet and fasting. Lab Anim 1987; 21: 216222

[35] Komori M, Kikuchi O, Sakuma T, Funaki J, Kitada M, Kamataki T. Molecular cloning of monkey liver cytochrome P450 cDNAs: similarity of the primary sequences to human cytochromes P450. Biochim Biophys Acta 1992; 1171: 141-146

[36] Trisomboon H, Malaivijitnond S, Watanabe G, Cherdshewasart W, Taya K. The Estrogenic effect of Pueraria mirifica on gonadotrophin levels in aged monkeys. Endocrine 2006; 29: 129-134

[37] Kittivanichkul D, Charoenphandhu N, Malaivijitnond S. Pueraria mirifica alleviates cortical bone loss in naturally menopausal monkeys. J Endocrinol 2016; 231: 121-133

[38] Satoh H, Nomiya N, Imai D, Sato S, Sakurai K, Takasuna K, Furuhama K. A method for estimating the glomerular filtration rate in conscious monkeys. J Appl Toxicol 2016; 36: 266-270

[39] David MP, Christain JT, Zhongze MA, Machael TBA, David YWL, Scott EL. Pharmacokinetic profile of the isoflavone puerarin after acute and repeated administration of a novel kudzu extract to human volunteers. J Altern Complement Med 2006; 12: 543-548 
[40] Khemawoot P, Saunders D, Rasameesorai M, Melendez V, Imerbsin R, Ohrt C, Fracisco S, Teja-Isavadharm P. Absolute bioavailability of cismirincamycin and trans-mirincamycin in healthy rhesus monkeys and ex vivo antimalarial activity against Plasmodium falciparum. Antimicrob Agents Chemother 2011; 55: 5881-5886

[41] Takahashi M, Washio T, Suzuki N, Igeta K, Fujii Y, Hayashi M, Shirasaka Y, Yamashita S. Characterization of gastrointestinal drug absorption in cynomolgus monkeys. Mol Pharm 2008; 5: 340-348

[42] Krause W, Kuhne G, Schillinger E. Pharmacokinetics and biotransformation of methane sulphonanilides with anti-inflammatory activity in the rat and monkey - comparison with piroxicam. Xenobiotica 1983; 13 : 265-272

[43] Wang Q, Wu Y, Xiang F, Feng Y, Li Z, Ding Y. Effects of puerarin on the pharmacokinetics of triptolide in rats. Pharm Biol 2019; 57: 407-411

[44] Thiebut F, Tsuruo T, Hamada H, Gottesman MM, Pastan I, Willingham MC. Cellular localization of the multidrug resistence gene product P-glycoprotein in normal human tissues. Proc Natl Acad Sci US A 1987; 84: 7735-7738

[45] Paine MF, Hart HL, Ludington SS, Haining RL, Rettie AD, Zeldin DC. The human intestinal cytochrome P450 “pie". Drug Metab Dispos 2006; 345: 880-886

[46] Thummel KE. Gut instincts: CYP3A4 and intestinal drug metabolism. J Clin Invest 2007; 117: 3173-3176

[47] Zhang L. Pharmacokinetics and drug delivery systems for puerarin, a bioactive flavone from traditional Chinese medicine. Drug Deliv 2019; 26: 860-869

[48] Luo CF, Cai B, Hou N, Yuan M, Liu SM, Ji H, Xiong LG, Xiong W, Luo JD, Chen MS. UDP-glucuronosyltransferase $1 \mathrm{~A} 1$ is the principal enzyme responsible for puerarin metabolism in human liver microsomes. Arch Toxicol 2012; 86: 1681-1690 